\title{
ANALISIS GAYA BELAJAR VISUAL, AUDIOTORI DAN KINESTETIK DALAM PENGEMBANGAN PRESTASI BELAJAR SISWA
}

\author{
Susi Lestari ${ }^{1}$, Muhammad Widda Djuhan ${ }^{2}$ \\ ${ }^{1}$ Institut Agama Islam Negeri Ponorogo, \\ Susilestari0806@gmail.com \\ ${ }^{2}$ Institut Agama Islam Negeri Ponorogo, \\ widdhadjuhan99@gmail.com
}

\begin{abstract}
ABSTRAK
Penelitian ini dilatarbelakangi oleh prestasi belajar pada mata pelajaran IPS di SMPN 1 Purwantoro dapat dikategorikan kurang, dibandingkan dengan mata pelajaran yang lainnya. Hal ini dikarenakan pada proses belajar di dalam kelas kurang membuat siswa tertarik akan gaya mengajar yang diterapkan oleh guru. Penelitian ini bertujuan: Untuk mengetahui bentuk gaya belajar Visual, audiotori dan kinestetik siswa dalan pengembangan prestasi belajar siswa pada mata pelajaran IPS.Rancangan dalam penelitian ini peneliti menggunakan pendekatan kualitatif dengan metode pengumpulan data berupa wawancara, observasi, dan dokumentasi. Penelitian ini dilakukan di SMPN 1 Purwantoro dengan subjek penelitian siswa kelas VIII E berjumlah 32 siswa.Hasil penelitian dalam rumusan masalah pertama yaitubentuk gaya belajar visual dalam pengembangan prestasi belajar pada mata pelajaran IPS di SMPN 1 purwantoro dengan materi pelaku ekonomi antara lain: (1) belajar dengan menggunakan papan tulis dan LCD, (2) belajar dengan meringkas materi, (3) belajar dengan melihat video.Hasil penelitian dalam rumusan masalah kedua yaitubentuk gaya belajar audiotori siswa dalam pengembangan mata pelajaran IPS di SMPN 1 Purwantoro yaitu: (1) belajar dengan diskusi bersama, (2) belajar sambil mendengarkan musik. Hasil penelitian ketiga yaitu bentuk gaya belajar siswa yang mempunyai gaya belajar kinestetik adalah: (1) belajar dengan menggunakan bahasa tubuh (2) membaca sambil berjalan. Hasil penelitian dalam rumusan masalah keempat yaitu hasil dari gaya belajar visual, audiotori dan kinestetik masing-masing siswa mempunyai nilai yang baik pada gaya belajar yang cenderung dimiliki oleh masing-masing siswa tersebut.
\end{abstract}

Kata kunci :Gaya Belajar, Visual, Audiotori, Kinestetik, Siswa.

\section{ABSTRACT}

This research is motivated by the learning achievement in social studies subjects at SMPN 1 Purwantoro which can be categorized as less, compared to other subjects. This is because the learning process in the classroom does not make students interested in the teaching style applied by the teacher. This study aims: To determine the form of visual, audiotory and kinesthetic learning styles of students in developing student achievement in social studies subjects. The design in this study the researcher used a qualitative approach with data collection methods in the form of interviews, observation and documentation. This research was conducted at SMPN 1 Purwantoro with 32 students as the subject of research in class VIII E. The results of the research in the formulation of the first problem, namely the form of visual learning styles in the development of learning achievement in social studies subjects at SMP 1 Purwantoro with the material of economic actors include: (1) learning using a blackboard and LCD, (2) learning by summarizing the material, (3) ) learn by watching videos. The results of the research in 
the formulation of the second problem were the form of students' audiotory learning styles in the development of social studies subjects at SMPN 1 Purwantoro, namely: (1) learning by discussion, (2) learning while listening to music. The results of the third study, namely the form of student learning styles that have kinesthetic learning styles are: (1) learning by using body language (2) reading while walking. The results of the research in the formulation of the fourth problem, namely the results of the visual, audiotory and kinesthetic learning styles of each student have a good value on the learning styles that each student tends to have.

Keywords: Learning Style, Visual, Audiotory, Kinesthetic, Student.

\section{PENDAHULUAN}

\section{A. Latar Belakang Masalah}

Prestasi belajar adalah penguasaan pengetahuan atau keterampilan yang dikembangkan oleh mata pelajaran lazimnya ditunjukan dengan nilai tes atau angka yang diberikan oleh guru. Penilaian prestasi belajar siswa dinilai pada aspek kognitif dengan ditunjukannya kemampuan siswa dalam pengetahuan atau ingatan, pemahaman, aplikasi, analisis, sintesa, dan evaluasi. Bukti dari meningkat atau tidaknya prestasi belajar siswa ditunjukan melalui nilai atau angka nilai dari hasil evaluasi yang telah dilakukan oleh guru terhadap tugas siswa dan ulangan-ulangan atau ujian yang ditempuhnya. ${ }^{1}$

Prestasi belajar pada mata pelajaran IPS di SMPN 1 Purwantoro dapat dikategorikan kurang, dibandingkan dengan mata pelajaran yang lainnya. Hal ini dikarenakan pada proses belajar di dalam kelas kurang membuat siswa tertarik akan gaya mengajar yang diterapkan oleh guru. Pembelajaran yang terlalu monoton dan terlalu banyak materi yang susah dipahami. Siswa membutuhkan sesuatu yang baru untuk menumbuhkan minat belajar dan meningkatkan prestasi belajar khususnya pada mata pelajaran IPS. ${ }^{2}$

Gaya belajar menjadi aspek penting yang harus diperhatikan oleh guru dan siswa karena gaya belajar menjadi kunci keberhasilan belajar siswa. guru sebaiknya mengetahui perbedaan gaya belajar masing-masing siswa sehingga siswa dapat belajar aktif dan efektif. Seseorang dikatakan guru yang sukses apabila mengetahui apa yang dibutuhkan siswa dan memperlakukan mereka sesuai apa yang mereka butuhkan termasuk gaya belajar. Oleh karena itu, guru harus melakukan identifikasi gaya belajar siswa yang diajarnya agar mengetahui kecenderungan gaya belajar siswa yang diajarnya. Seorang guru

${ }^{1}$ Tulus Tu'u, Peran Disiplin pada Perilaku dan Prestasi Siswa, ( Jakarta: Grasindo, 2008),

${ }^{2}$ Wawancara dengan siswa.
} 
yang mengetahui kecenderungan gaya belajar siswa maka pembelajaran yang dibuat akan memenuhi kebutuhan siswa dan pembelajaran akan efektif sehingga akan memperoleh hasil belajar yang lebih baik. ${ }^{3}$

Barbara Prashnig mengungkapkan bahwa gaya belajar siswa yang sesuai dengan cara mereka melakukan kegiatan belajar akan memberikan dampak positif bagi mereka, bukan hanya memberi perbaikan yang cepat, namun terlebih lagi akan menjadikan obat dalam jangka panjang bagi siswa yang selalu berusaha berprestasi di sekolah. Barbara Prashnig juga mengatakan bahwa peran guru dalam proses belajar siswa di sekolah sangat mempengaruhi terhadap kesuksesan anak didiknya. Hal ini bisa terjadi karena disamping peran guru sebagai perantara transfer ilmu bagi siswa, guru juga dituntut sebagai pengawas dalam kegiatan belajar siswa, oleh karena itu, guru harus memahami gaya belajar setiap siswanya agar guru dapat menciptakan suasana belajar yang multi indrawi dan dapat melayani sebaik mungkin atas kebutuhan individual setiap siswa. Memahami gaya belajar merupakan strategi yang digunakan oleh gurupun tidak hanya monoton, melainkan ada variasi dan inovasi guru dalam pembelajaran kelas, sehingga gaya mengajar guru akan lebih efektif dan siswapun akan menjadi pelajar yang lebih percaya diri dan lebih puas dengan kemajuan belajar mereka. ${ }^{4}$

Gaya belajar yang variatif memungkinkan siswa dapat menyerap informasi atau materi pembelajaran dengan mudah. Daya serap siswa yang berbeda membuat informasi atau pelajaran yang diberikan oleh guru dengan satu gaya belajar memungkinkan siswa di dalam kelas tidak semua dapat menyerap informasi atau materi pembelajaran yang diberikan oleh guru. Guru harus mampu menerapkan tiga gaya belajar yang dimiliki oleh siswa di dalam kelas tersebut. Gaya belajar tersebut diantaranya: (1) Gaya belajar visual, (2) Gaya belajar audiotori dan (3) Gaya belajar kinestetik.

Gaya belajar visual yaitu belajar melalui melihat, memandangi, mengamati, dan sejenisnya. Lebih tepatnya tipe belajar visual adalah belajar dengan melihat sesuatu, baik berupa gambar atau diagram, pertunjukan, atau

${ }^{3}$ Yeni Putri Puspandari et al, identifikasi gaya belajar siswa akuntansi tahun pelajaran 2017/2018. Pendidikan Akuntansi. Jurnal "Tata Arta" UNS, Vol. 3 , No. 2, hlm. 138.

4 Ali Murfi dan Noneng Siti Rosidah, Analisis Gaya Belajar Siswa Berprestasi Studi Komparasi Siswa Berprestasi SMAN 1 dengan MAN 1 Yogyakarta Kelas XI. Jurnal Pendidikan Madrasah, Vol. 1, No. 2, 2016, 297. 
video. Orang-orang dengan tipe ini lebih menyukai belajar maupun menerima informasi dengan melihat atau membaca. Setelah melihat atau membaca, orang-orang ini akan lebih mudah dan cepat dalam mencerna informasi serta mengolah informasi baru yang diterima. ${ }^{5}$

Gaya belajar audiotori adalah tipe belajar yang mengedepankan indera pendengar. Belajar melalui mendengar sesuatu, bisa dengan mendengarkan kaset, kuliah-ceramah, diskusi, debat, dan instruksi (perintah) verbal. Orangorang yang dengan tipe belajar audiotorik lebih mudah mencerna, mengolah, dan menyampaikan informasi dengan jalan mendengarkan secara langsung. Mereka cenderung belajar atau menerima informasi dengan mendengarkan atau secara lisan. ${ }^{6}$

Gaya belajar kinestetik adalah belajar dengan melakukan aktifitas fisik dan keterlibatan langsung, yang bisa berupa "menangani”, bergerak, menyentuh, dan merasakan/mengalami sendiri. Siswa yang mempunyai gaya belajar kinestetik tidakn tahan duduk terlalu lama saat mendengarkan pelajaran dan merasa bisa belajar lebih baik jika prosesnya disertai kegiatan fisik. Kelebihannya, mereka memiliki kemampuan mengkoordinasikan sebuah tim disamping kemampuan mengendalikan gerak tubuh. ${ }^{7}$

Gaya belajar siswa yang diterapkan pada mata pelajaran IPS di SMP Negeri 1 Purwantoro dalam mengatasi kurangnya dan turunnya prestasi belajar siswa menjadi daya tarik peneliti guna dijadikan bahan penelitian untuk memenuhi tugas akhir. Maka peniliti mengangkat judul skripski "Analisis Gaya Belajar Visual, Audiotori Dan Kinestetik Dalam Pengembangan Prestasi Belajar Siswa"

\section{B. Tujuan Penelitian}

Berdasarkan rumusan masalah diatas maka penelitian ini bertujuan untuk:

1. Untuk mengetahui bentuk gaya belajar Visual siswa dalan pengembangan prestasi belajar siswa pada mata pelajaran IPS di SMPN 1 Purwantoro.

\footnotetext{
${ }^{5}$ S. Shoimatul Ula, REVOLUSI BELAJAR Optimalisasi Kecerdasan melalui Pembelajaran Berbasis Kecerdasan Majemuk, (Yogyakarta: Ar-Ruzz Media,2013), 31.

${ }^{6}$ Ibid., 33.

${ }^{7}$ Jurnal Kopasta.
} 
2. Untuk mengetahui bentuk gaya belajar audiotori siswa dalan pengembangan prestasi belajar siswa pada mata pelajaran IPS di SMPN 1 Purwantoro.

3. Untuk mengetahui bentuk gaya belajar kinestetik siswa dalan pengembangan prestasi belajar siswa pada mata pelajaran IPS di SMPN 1 Purwantoro.

4. Untuk mengetahui hasil belajar visual, audiotori, dan kinestetik dalam mengembangkan prestasi belajar siswa di SMPN 1 Purwantoro.

\section{METODE PENELITIAN}

Jenis penelitian yang akan dilakukan penulis adalah Penelitian Kualitatif. ${ }^{8}$ Jenis pendekatan penelitian yang peneliti ambil yaitu jenis penelitian studi kasus, penelitian ini bertujuan untuk mengembangkan metode kerja yang paling efisien , maknanya peneliti mengadakan telaah secara mendalam tentang suatu kasus, kesimpulannya hanya berlaku atau berbatas pada kasus tertentu saja. ${ }^{9}$ Tempat penelitian atau lokasi penelitian adalah di SMP Negeri 1 Purwantoro dengan penelitian di kelas $8 \mathrm{E}$ jumlah siswa sebanyak 32 siswa. Teknik pengumpulan data dengan menggunakan wawancara, dokumentasi dan observasi.

Teknik analisis data dalam kasus ini menggunakan analisis data kualitatif, konsep ini Miles dan Huberman, bahwa aktivitas dalam analisis data kualitatif dilakukan secara interaktif dan berlangsung secara terus menerus pada setiap tahapan penelitian, sehingga sampai tuntas. ${ }^{10}$

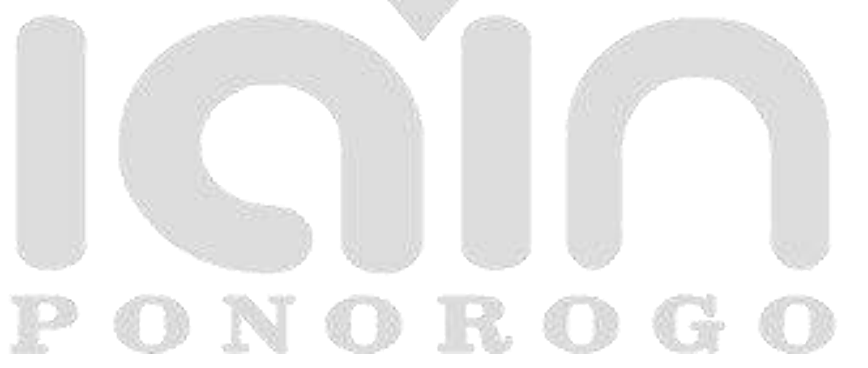

\footnotetext{
${ }^{8}$ Andi Prastowo, Metode Penelitian Kualitatif Dalam Perspektif Rancangan Penelitian, cet ke 3 (Jogjakarta: AR-RUZZ MEDIA, 2014), 21.

${ }^{9}$ Iskandar, PSIKOLOGI PENDIDIKAN Sebuah Orientasi Baru, (Jakarta: Refrensi, 2012), 26.

${ }^{10}$ Sugiyono, Metedologi Penelitian Kuantitatif, Kualitatif, Dan R\&D (Bandung: ALFABETA, 2012), 335.
} 


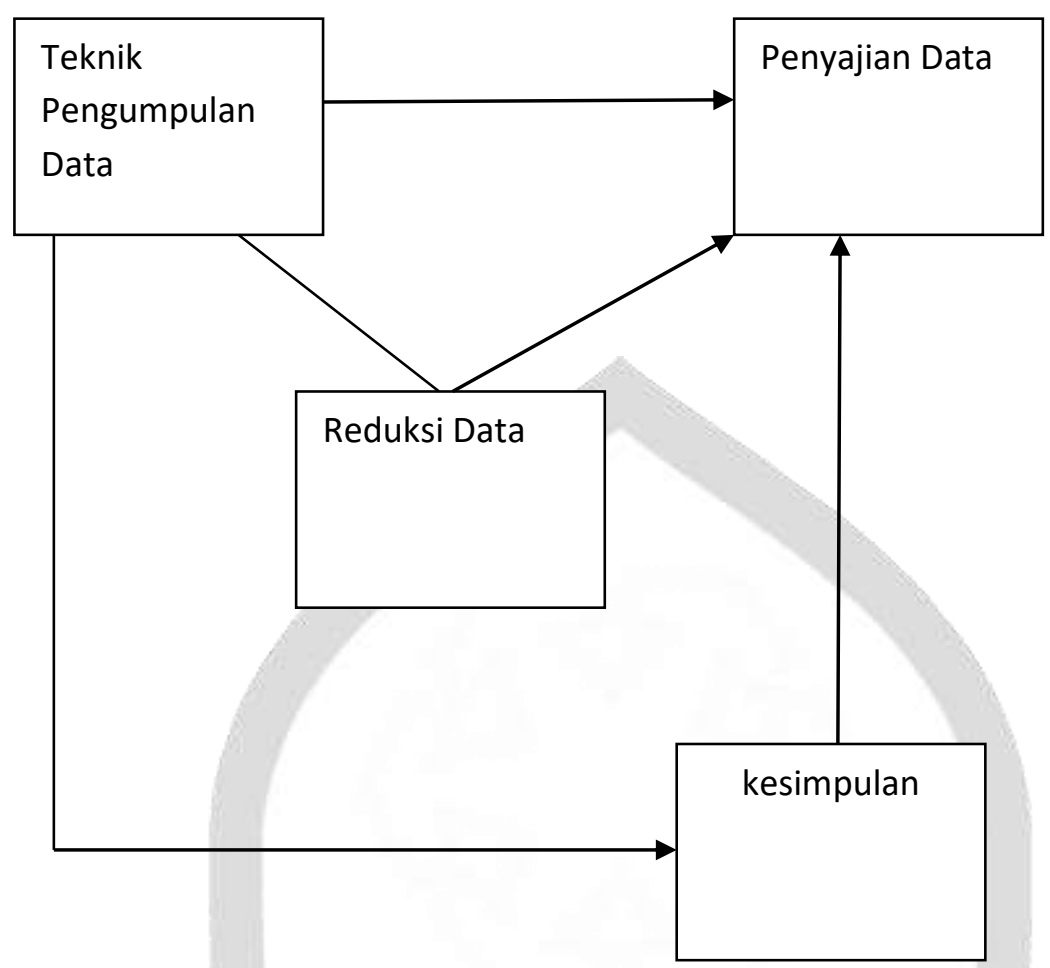

Teknik analisis data dalam kasus ini menggunakan analisis data kualitatif, konsep ini Miles dan Huberman, bahwa aktivitas dalam analisis data kualitatif dilakukan secara interaktif dan berlangsung secara terus menerus pada setiap tahapan penelitian, sehingga sampai tuntas.

\section{HASIL DAN PEMBAHASAN}

Gaya belajar dapat didefinisikan dengan berbagai cara, tergantung pada perspektif seseorang. Keefe (1979) mendefinisikan gaya belajar sebagai "gabungan dari karakteristik kognitif, afektif, dan faktor fisiologis yang berfungsi sebagai indikator yang relatif stabil tentang bagaimana pelajar merasakan, berinteraksi dengan, dan merespon lingkungan belajar”. Brown (2000) mendefinisikan gaya belajar sebagai cara seseorang mempersepsikan dan memproses informasi dalam situasi belajar. Brown berpendapat bahwa preferensi gaya belajar merupakan salah satu aspek gaya belajar, dan mengacu pada pilihan satu stuasi belajar atau kondisi di atas preferensi yang lain.Dengan kata lain, gaya belajar adalah cara seorang siswa merasakan, berinteraksi dengan, dan merespon lingkungan belajar. Gaya belajar kadang-kadang didefinisikan sebagai karakteristik kognitif, afektif, sosial, dan fisiologis perilaku yang berfungsi 
sebagai indikator yang relatif stabil tentang bagaimana siswa merasakan, berinteraksi dengan, dan menanggapi lingkungan belajar" 11

\section{A. Bentuk gaya belajar visual siswa dalam pengembangan prestasi belajar siswa pada mata pelajaran IPS di SMPN 1 Purwantoro}

Siswa yang bergaya belajar visual, yang memegang peranan penting adalah mata atau penglihatan (visual). Mereka cenderung belajar melalui apa yang mereka lihat. Siswa mempunyai gaya belajar visual harus melihat bahasa tubuh dan ekspresi wajah gurunya untuk mengerti materi pelajaran. Mereka cenderung untuk duduk di depan agar dapat melihat dengan jelas. Mereka berpikir menggunakan gambar-gambar di otak mereka dan belajar lebih cepat dengan menggunakan tampilan-tampilan visual, seperti diagram, buku pelajaran bergambar, dan video.Di dalam kelas, anak visual lebih suka mencatat sampai detail-detailnya untuk mendapatkan informasi. ${ }^{12}$

Berdasarkan hasil observasi peneliti bentuk gaya belajar visual dalam pengembangan prestasi belajar pada mata pelajaran IPS di SMPN 1 purwantoro dengan materi pelaku ekonomi antara lain: (1) belajar dengan menggunakan papan tulis dan LCD, (2) belajar dengan meringkas materi yang telah disampaikan, (3) belajar dengan melihat video.

Pada penemuan diatas dapat disimpulkan bahwa gaya belajar visual mampu mengembangkan prestasi belajar siswa pada mata pelajaran IPS di SMP Negeri 1 Purwantoro. Dibuktikan dengan adanya persamaan antara teori dengan hasil observasi yang telah dilakukan oleh peneliti. Pada teori diatas disebutkan bahwasiswa berpikir menggunakan gambar-gambar di otak mereka dan belajar lebih cepat dengan menggunakan tampilan-tampilan visual, seperti diagram, buku pelajaran bergambar, dan video.Di dalam kelas, anak visual lebih suka mencatat sampai detail-detailnya untuk mendapatkan informasi. Sedangkanpenemuan yang ditemukan oleh peneliti di SMPN 1 Purwantoro pembelajaran yang dilakukan oleh guru dengan menggunakan gaya belajar visual adalah (1) belajar dengan mengunakan papan tulis dan LCD, (2) belajar dengan meringkas materi yang telah disampaikan, (3) belajar dengan melihat video.

11 Pangesti Wiedarti, pentingnya memahami gaya belajar, (Jakarta: Direktorat jendral pendidikan dasar dan menengah kementerian pendidkian dan kebudayaan, 2018), 1-2.

12 Junierissa Marpaung, Pengaruh Gaya Belajar Terhadap Prestasi Belajar Siswa, Univercity Of Kepulauan Riau, Batam, Jurnal Kopasta, Vol. 2 (2). 2015, 84 


\section{B. Bentuk gaya belajar audiotori siswa dalam pengembangan prestasi belajar siswa}

Pada bentuk gaya belajar audiotori siswa sangat senang melakukan apa yang mereka dengar. Tipe ini sangat mempunyai kendala sering lupa apayang dijelaskan guru, sering lupa membuattugas yang diinstruksikan guru secara lisan, kerap kelirumengerjakan seperti yang diperintahkan guru, dan kesulitanmengekspresikan apa yang dipikirkan. Pada gaya audiotori siswa memiliki ciri-ciri mudah belajar dan mengingat dengan cara mendengarkan, misalnya saja siswa lebih mudah belajar dengan berdialog atau berdiskusi. ${ }^{13}$

Berdasarkan hasil observasi penelitibentuk gaya belajar audiotori siswa dalam pengembangan mata pelajaran IPS di SMPN 1 Purwantoro yaitu: (1) belajar dengan diskusi bersama, (2) belajar sambil mendengarkan musik.Langkah-langkah yang digunakan pak bimo dalam pembelajaran meinggunakan gaya belajar audiotori yaitu: (1) siswa membentuk kelompok masing-masing kelompok terdiri dari 4 siswa. (2) Guru memberikan materi kepada masing-masing kelompok. (3) setelah selesai diskusi, Guru menunjuk acak siswa untuk menjelaskan materi yang telah didiskusikan oleh masingmasing siswa.

Pada penemuan diatas dapat disimpulkan bahwa gaya belajar audiotorimampu mengembangkan prestasi belajar siswa pada mata pelajaran IPS di SMP Negeri 1 Purwantoro. Dibuktikan dengan adanya persamaan antara teori dengan hasil observasi yang telah dilakukan oleh peneliti. Pada teori diatas disebutkan bahwa siswamudah belajar dan mengingat dengan cara mendengarkan, misalnya saja siswa lebih mudah belajar dengan berdialog atau berdiskusi. Sedangkanpenemuan yang ditemukan oleh peneliti di SMPN 1 Purwantoro pembelajaran yang dilakukan oleh guru dengan menggunakan gaya belajar audiotori adalah: (1) belajar dengan diskusi bersama, (2) belajar sambil mendengarkan musik.Langkah-langkah yang digunakan pak bimo dalam pembelajaran meinggunakan gaya belajar audiotori yaitu: (1) siswa membentuk kelompok masing-masing kelompok terdiri dari 4 siswa. (2) Guru memberikan materi kepada masing-masing kelompok. (3) setelah selesai

13 Agusta Kurniati et. al. Analisis gaya belajar siswa pada mata pelajaran bahasa indonesia kelas V. Vol 5. 2019, 90. 
diskusi, Guru menunjuk acak siswa untuk menjelaskan materi yang telah didiskusikan oleh masing-masing siswa.

\section{Bentuk gaya belajar Kinestetik siswa dalam pengembangan prestasi belajar siswa pada mata pelajaran IPS di SMPN 1 Purwantoro}

Gaya belajar kinestetik merupakan gaya belajar yang mengarah pada gerakan. Anak cenderung tidak bisa diam. Anak dengan gaya belajarseperti ini tidak bisa belajar di sekolah-sekolah yang bergayakonvensional di mana guru menjelaskan dan anak duduk diam.Anak akan lebih cocok dan berkembang bila di sekolah dengansistem active learning, dimana anak banyak terlibat dalam proses belajar.Siswa akan lebih mudah menangkap pelajaran apabila mereka bergerak, meraba, atau mengambil tindakan. ${ }^{14}$

Berdasarkan hasil observasi penelitibentuk gaya belajar siswa yang mempunyai gaya belajar kinestetik adalah: (1) belajar dengan menggunakan bahasa tubuh (2) membaca sambil berjalan. (3) Guru mengembangkan gaya belajar kinestetik siswa dengan mengamati lingkungan sekitar dan dikaitkan dengan materi pelajaran IPS.

Pada penemuan diatas dapat disimpulkan bahwa gaya belajar kinestetik mampu mengembangkan prestasi belajar siswa pada mata pelajaran IPS di SMP Negeri 1 Purwantoro. Dibuktikan dengan adanya persamaan antara teori dengan hasil observasi yang telah dilakukan oleh peneliti. Pada teori diatas disebutkan bahwa gaya belajar kinestetik merupakan gaya belajar yang mengarah pada gerakan.Anak akan lebih cocok dan berkembang bila di sekolah dengansistem active learning, dimana anak banyak terlibat dalam proses belajar. Siswa akan lebih mudah menangkap pelajaran apabila mereka bergerak, meraba, atau mengambil tindakan. Sedangkanpenemuan yang ditemukan oleh peneliti di SMPN 1 Purwantoro pembelajaran yang dilakukan oleh guru dan wawancara dengan siswa menggunakan gaya belajar kinestetik adalah (1) belajar dengan menggunakan bahasa tubuh (2) membaca sambil berjalan. (3) Guru mengembangkan gaya belajar kinestetik siswa dengan mengamati lingkungan sekitar dan dikaitkan dengan materi pelajaran IPS.

\footnotetext{
${ }^{14}$ Agusta Kurniati et, al, 92.
} 


\section{Hasil gaya belajar visual, audiotori, dan kinestetik dalam pengembangan prestasi belajar siswa di SMPN 1 Purwantoro}

Gaya belajar setiap siswa berbeda-beda, dan masing-masing gaya belajartersebut memiliki nilai positif dan negatif, begitu juga dengan dampaknya kepada orang tersebut dan disekelilingnya. Siswa yang tidak mengenal gaya belajarnya akan menghasilkan prestasi belajar yang buruk. Selain itu tentu saja mutu pendidikan yang baik juga mempengaruhi gaya belajar siswa, begitu juga dengan lingkungan siswa tersebut. Namun motivasi yang tinggi bagi siswa untuk mengembangkan gaya belajar sangat mendukung untuk mencapai prestasi belajar. Hal ini berarti setiap orang mempunyai gaya belajar yang berbeda-beda. ${ }^{15}$

Rahasia keberhasilan pembelajaran terletak pada pengenalan seseorang terhadap dirinya sendiri, kesesuaian gaya mengajar dan gaya belajar, potensinya, dan konsekuensi yang ditimbulkannya. Hampir semua siswa yang berprestasi rendah adalah siswa yang gaya belajarnya tidak cocok dengan gaya mengajar guru di sekolah.

Pada penemuan diatas dapat disimpulkan bahwa siswa di SMP Negeri 1 Purwantoro memiliki gaya belajar yang berbeda-beda. Hasil dari penelitian yang peneliti lakukan untuk melihat gaya belajar siswa yaitu siswa yang cenderung mempunyai gaya belajar visual jumlah 20 siswa, siswa yang cenderung mempunyai gaya belajar audiotori berjumlah 6 siswa, sedangkan siswa yang cenderung mempunyai gaya belajar kinestetik berjumlah 6 siswa. Siswa yang cenderung mempunyai gaya belajar visual mempunyai nilai yang baik pada saat guru menerapkan/menggunakan gaya belajar visual (menggunkan LCD dan papan tulis) pada saat proses belajar mengajar. Begitupun, jika guru menggunakan gaya belajar audiotori (metode diskusi) siswa yang cenderung mempunyai gaya belajar audiotori mendapatkan nilai yang baik dibandingkan ketika guru menggunakan gaya belajar lainnya. Sama halnya dengan siswa yang cenderung mempunyai gaya belajar kinestetik, nilai yang siswa dapatkan ketika guru menggunakan gaya belajar kinestetik pada materi yang sedang dipelajari dapat membantu mengembangkan prestasi belajar siswa khususnya pada mata pelajaran IPS. Jika ditarik kesimpulan

15 Junierissa Marpaung, Pengaruh Gaya Belajar Terhadap Prestasi Belajar Siswa, Univercity Of Kepulauan Riau, Batam, Jurnal Kopasta, Vol. 2 (2). 2015, 86. 
masing-masing gaya belajar siswa baik gaya belajar visual, audiotori dan kinestetik dapat membantu mengembangkan prestasi belajar siswa, jika guru mampu menempatkan gaya belajar tersebut sesuai pada materi yang tengah dipelajari oleh siswa, agar siswa mampu mengembangkan prestasi belajar pada mata pelajaran IPS.

Pada penemuan diatas dapat disimpulkan bahwa ada keterkaitan antara keberhasilan pembelajaran siswa terletak pada pengenalan seseorang terhadap dirinya sendiri, kesesuaian gaya mengajar dan gaya belajar, potensinya, dan konsekuensi yang ditimbulkannya. Hampir semua siswa yang berprestasi rendah adalah siswa yang gaya belajarnya tidak cocok dengan gaya mengajar guru di sekolah. Dibuktikan dengan adanya persamaan antara teori dengan hasil observasi yang telah dilakukan oleh peneliti. Hasil dari penelitian yang peneliti lakukan untuk melihat gaya belajar siswa yaitu siswa yang cenderung mempunyai gaya belajar visual jumlah 20 siswa, siswa yang cenderung mempunyai gaya belajar audiotori berjumlah 6 siswa, sedangkan siswa yang cenderung mempunyai gaya belajar kinestetik berjumlah 6 siswa. Siswa yang cenderung mempunyai gaya belajar visual mempunyai nilai yang baik pada saat guru menerapkan/menggunakan gaya belajar visual (menggunkan LCD dan papan tulis) pada saat proses belajar mengajar. Begitupun, jika guru menggunakan gaya belajar audiotori (metode diskusi) siswa yang cenderung mempunyai gaya belajar audiotori mendapatkan nilai yang baik dibandingkan ketika guru menggunakan gaya belajar lainnya. Sama halnya dengan siswa yang cenderung mempunyai gaya belajar kinestetik, nilai yang siswa dapatkan ketika guru menggunakan gaya belajar kinestetik pada materi yang sedang dipelajari dapat membantu mengembangkan prestasi belajar siswa khususnya pada mata pelajaran IPS. Jika ditarik kesimpulan masing-masing gaya belajar siswa baik gaya belajar visual, audiotori dan kinestetik dapat membantu mengembangkan prestasi belajar siswa, jika guru mampu menempatkan gaya belajar tersebut sesuai pada materi yang tengah dipelajari oleh siswa, agar siswa mampu mengembangkan prestasi belajar pada mata pelajaran IPS.

\section{PENUTUP}

Hasil penelitian menunjukkan bahwa gaya belajar visual, audiotori dan kinestetik siswa dapat membantu mengembangkan prestasi belajar siswa di SMP 
Negeri 1 Purwantoro. Hal ini dibuktikan dengan penelitian yang dilakukan oleh peneliti dengan adanya peningkatan prestasi belajar sesuai dengan gaya belajar yang dimiliki siswa. Hal ini disebabkan dengan penyampaian materi yang dilakukan oleh guru disesuaikan dengan gaya belajar yang dicocok dalam penyampaian materi kepada peserta didik dalam membantu mengembangkan prestasi belajar peserta didik.

\section{DAFTAR PUSTAKA}

Iskandar. PSIKOLOGI PENDIDIKAN Sebuah Orientasi Baru. Jakarta: Refrensi. 2012

Sugiyono.Metedologi Penelitian Kuantitatif, Kualitatif, Dan $R \& D$. Bandung: ALFABETA. 2012

Kumiati. Agusta et. al. Analisis gaya belajar siswa pada mata pelajaran bahasa indonesia kelas V. Vol 5. 2019

Marpaung. Junierissa. Pengaruh Gaya Belajar Terhadap Prestasi Belajar Siswa. Univercity Of Kepulauan Riau. Batam. Jurnal Kopasta. Vol. 2 (2). 2015

Murfi. Ali dan Noneng Siti Rosidah.Analisis Gaya Belajar Siswa Berprestasi Studi Komparasi Siswa Berprestasi SMAN 1 dengan MAN 1 Yogyakarta Kelas XI. Jurnal Pendidikan Madrasah, Vol. 1, No. 2, 2016

Prastowo. Andi. Metode Penelitian Kualitatif Dalam Perspektif Rancangan Penelitian. Jogjakarta: AR-RUZZ MEDIA. 2016

Puspandari. Yeni Putri et al.identifikasi gaya belajar siswa akuntansi tahun pelajaran 2017/2018. Pendidikan Akuntansi. Jurnal "Tata Arta” UNS, Vol. 3 , No. 2

Sukardi.METODOLOGI PENELITIAN PENDIDIKAN Kompetensi dan Praktiknya. Yogyakarta. Bumi Aksara. 2003

Tu'u, Tulus. Peran Disiplin pada Perilaku dan Prestasi Siswa. Jakarta: Grasindo. 2008

Ula. S. Shoimatul. REVOLUSI BELAJAR Optimalisasi Kecerdasan melalui Pembelajaran Berbasis Kecerdasan Majemuk. Yogyakarta: Ar-Ruzz Media. 2013 